\title{
Ceramic based pressure sensor with highly sensitive thin film
}

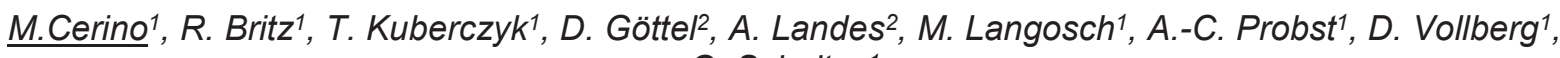 \\ G. Schultes ${ }^{1}$ \\ ${ }^{1}$ Hochschule für Technik und Wirtschaft HTW saar, Goebenstr. 40, 66117 Saarbrücken, Germany, \\ mario.cerino@htwsaar.de \\ 2Zentrum für Mechatronik und Automatisierungstechnik ZeMA gGmbH, \\ Gewerbegebiet Eschberger Weg, 66121 Saarbrücken, Germany
}

\begin{abstract}
Nickel containing carbon layers (Ni:a-C:H), deposited under specific conditions in a combined PVD/CVD plasma process show strain sensitivities that are enhanced by a factor of 5 - 15 compared with today's standard sensor thin films. The strain sensitivity (gauge-factors) are about 20, in unpublished developments even about 30. An innovative technological approach for pressure sensors is presented using these Ni:a-C:H layers. Membrane and sensor body are based on the ceramic material $\mathrm{ZrO}_{2}$ stabilized with $\mathrm{Y}_{2} \mathrm{O}_{3}$ yielding very good mechanical properties. Due to the ceramics inherent electrical insulation and the use of advanced thin film technology a simplified set-up is feasible. The membrane carries a highly sensitive layer that is structured to a Wheatstone bridge just by some laser cuts. Electrical contacts are securely bonded directly onto the sensor layer without the need for contact layers. We further demonstrate a construction and assembling technique of the complete pressure sensor including threat and housing. First results for prototypes of pressure sensors with a nominal capacity of 100 bar are discussed.
\end{abstract}

Key words: Ni:a-C:H thin film, pressure sensor, $\mathrm{ZrO}_{2}$ ceramic, laser-based patterning, high sensitivity

\section{Introduction}

Applications for pressure sensors are constantly increasing. Sensors for pressures of some bar up to some thousand bar are being used in the car industry and for a multitude of industrial purposes. The spreading of technology has led to a uniform sensor design: a stainless steel body with a membrane on which a stack of thin films is deposited and processed. This stack comprises insulation

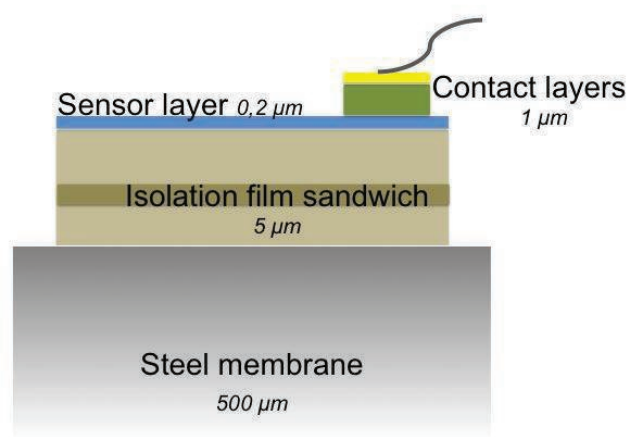

Fig. 1. Conventional thin film stack that is necessary if steel-membranes are used. films as well as a standard set of gauge, contact and protection films (see Fig. 1). After repeated photolithographic structuring the sensor body is welded onto a threat for further set-up. We verify a highly simplified approach by reducing to essential necessities (see Fig. 2 ). This approach is made possible by applying high performance ceramics, advanced thin film technology and structuring by ultrafast laser pulses.

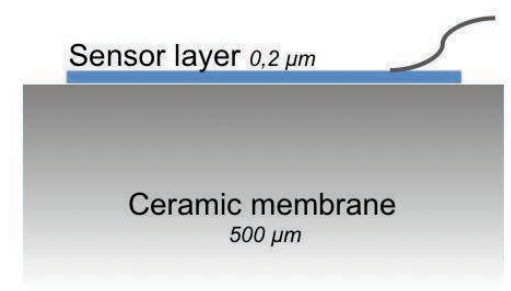

Fig. 2. The necessity for thin film technology is reduced to just one layer if a ceramic membrane and highly sensitive Ni:a-C:H are used. 


\section{Sensor design and set-up}

FE-Simulations with Comsol-Multiphysics were carried out to design a sensor with appropriate dimensions. Thus an outer diameter of $8 \mathrm{~mm}$ was chosen having two shoulders for the necessary seals. (see Fig. 4). The simulations were performed for two different ceramic materials; the standard ceramic $\mathrm{Al}_{2} \mathrm{O}_{3}$ and the high performance material $\mathrm{ZrO}_{2}$ stabilized with $\mathrm{Y}_{2} \mathrm{O}_{3}$. The relevant properties of those materials are listed in table 1.

Tab. 1 Properties of $\mathrm{Al}_{2} \mathrm{O}_{3}$ and $\mathrm{ZrO}_{2}$ stabilized with $\mathrm{Y}_{2} \mathrm{O}_{3}[1]$

\begin{tabular}{|c|c|c|}
\hline properties & $\begin{array}{l}\text { alumina } \\
\mathrm{Al}_{2} \mathrm{O}_{3} 99,7 \%\end{array}$ & $\begin{array}{l}\text { zirconia } \\
\text { Y-TZP } \\
3 \mathrm{~mol} \% \mathrm{Y}_{2} \mathrm{O}_{3}\end{array}$ \\
\hline $\begin{array}{c}\text { Compressive } \\
\text { strength }\end{array}$ & $3000 \mathrm{MPa}$ & $2200 \mathrm{MPa}$ \\
\hline $\begin{array}{c}\text { Young } \\
\text { modulus }\end{array}$ & $370 \mathrm{GPa}$ & $210 \mathrm{GPa}$ \\
\hline $\begin{array}{c}\text { Bending } \\
\text { strength }\end{array}$ & $350 \mathrm{MPa}$ & $1200 \mathrm{MPa}$ \\
\hline $\begin{array}{c}\text { Expansion } \\
\text { coefficient }\end{array}$ & $7.6 \mathrm{ppm} / \mathrm{K}$ & $10.5 \mathrm{ppm} / \mathrm{K}$ \\
\hline $\begin{array}{c}\text { Specific } \\
\text { resistance } \\
\left(20^{\circ} \mathrm{C}\right)\end{array}$ & $10^{14} \Omega \mathrm{cm}$ & $10^{9} \Omega \mathrm{cm}$ \\
\hline
\end{tabular}

The simulations for inner diameters of $3.5 \mathrm{~mm}$ were performed to yield a maximum strain of 1 per mille at the center of the membrane (see Fig. 3). Then two versions were manufactured (by the company MicroCeram), a $\mathrm{Al}_{2} \mathrm{O}_{3}$-version with a membrane thickness of $0.3 \mathrm{~mm}$ and a $\mathrm{ZrO}_{2}$-version with $0.5 \mathrm{~mm}$. The difference of the membrane thicknesses is due to the Young modulus of $370 \mathrm{GPa}$ and $210 \mathrm{GPa}$, respectively. We point out, that both versions are designed to have the same value of strain at the center of the membrane.

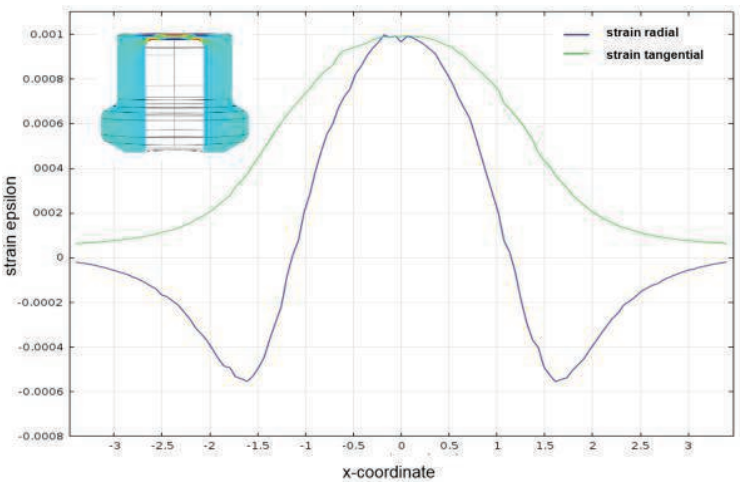

Fig. 3. FE- simulation of the ceramic cell (zirconia, $0.5 \mathrm{~mm}, 390 \mathrm{bar}$ )
The polished surface of the membrane is then equipped with just one functional layer of the highly sensitive granular metal Ni:a-C:H described elsewhere [2, 3]. In the next step, the deposited film with a thickness of approx. 200 $\mathrm{nm}$ is locally ablated by means of a picosecond laser. A Wheatstone bridge with two strain sensitive resistors in the center and two at the rim of the membrane is cut following a patented design $[4,5]$. After curing the cell, it is sealed and mounted onto a threaded connector of steel. This sealing with two metal gaskets between ceramic and steel (see Fig. 4) was designed according to the metal-ceramic join widespread in ignition plugs. Following this assembling procedure, the sensitive layer is securely contacted at four different potentials of the bridge by means of ultrasonic wedge bonding technique using Al-Si wires. The bonds connect the potentials to a printed circuit board carrying a signal processing unit to generate the standardized industrial interfaces.

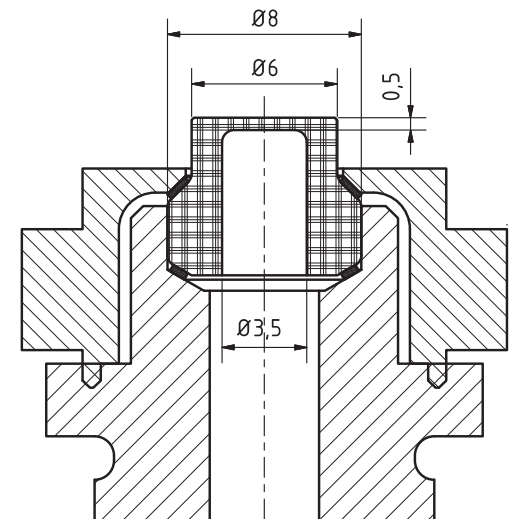

Fig. 4. Construction of the sensor with the ceramic cell and the assembling on a threaded connector.

\section{Highly sensitive thin film Ni:a-C:H}

Ni:a-C:H or nanoNi@C is a functional thin film that responds to mechanical strain five to fifteen times more sensitive than standard strain gauge materials such as $\mathrm{NiCr}$. It has a 5-15 fold increased strain sensitivity (gauge factor up to 30 ) and an adjustable temperature coefficient (TCR less than $\pm 25 \mathrm{ppm} / \mathrm{K}$ ).

\section{Laser-based patterning}

By using an ultrafast UV laser with a wavelength of $355 \mathrm{~nm}$ and a pulse duration of $<15$ ps, it is possible to cut the Ni:a-C:H layer without damaging the underlying ceramic cell. In figure 5 some laser cuts of the Ni:a-C:H coated measuring cell are demonstrated. The left-hand side of Fig. 5 shows some debris directly after the laser treatment, while the photo on the right-hand side was taken after 
cleaning. The width of the cuts which is defined by the laser spot diameter, can be varied from $10 \mu \mathrm{m}$ to higher values. The leakage current across the cut is measured with a Teraohmmeter contacting the two sides separated by one laser cut and applying 10 to $500 \mathrm{~V}$ DC. In each case a value exceeding $10^{9}$ $\Omega$ was measured. The residuals or debris caused by the laser ablation process can be completely removed by cleaning the ceramic cells in an ultrasonic bath with isopropanol. However, leakage faults could not be found neither before nor after cleaning.

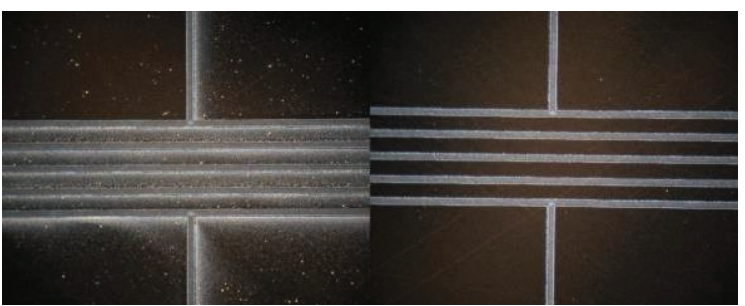

Fig. 5. Left: sample directly after the laser treatment and before cleaning, Right: after a cleaning procedure.

\section{Patented design}

The developed laser cutting geometry creates a Wheatstone bridge, which can be generated by a few laser cuts in the functional layer (see Fig. 6 and $[4,5])$. The resistors $R_{1}$ and $R_{2}$ are positioned in the compression zone of the membrane at the rim, while the resistors $R_{3}$ and $\mathrm{R}_{4}$ are located at the areas under tension near the center. The connecting paths are as broad as possible and are located on the membrane as well. The position marks represent symmetric contact positions for the electric connections via wedge bonds. The connecting paths for each resistor are realized by a broad and continuous area of the function layer from the positioning marks to the resistors. This ensures the maximum possible surface area and thus the smallest possible resistance of the connections. The laser cut which creates the resistors can be varied in length and width, hence it is feasible to raise or decrease the value of the resistance. By considering the sheet resistance of the function layer, values between $1 \mathrm{k} \Omega$ and $10 \mathrm{k} \Omega$ are achievable.

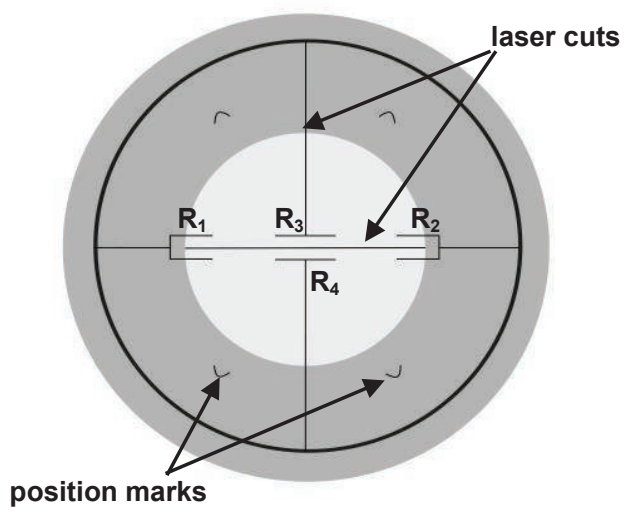

Fig. 6. Laser cut design of the thin film, on the membrane's top side of the ceramic cell. The thin zone of the membrane is colored light grey.

\section{Assembly of the ceramic cell with a steel connector}

For a quick change of the test samples avoiding a welding process (as suggested in Fig. 4), a demountable variant of the system was adopted. The assembly (see Fig. 7) consists of a threaded steel connector (1), two copper sealing rings (2), the ceramic pressure measuring cell (3) and a screw-on counterpart to fix the cell to the connector. The tightness of the assembly is realized by applying a proper torque onto the thread of the counterpart. In order to ensure a tight connection of up to 1000 bar of hydraulic pressure a necessary torque of approx. $10 \mathrm{Nm}$ was calculated. Some cells were mounted that way and the sealing concept could thus be verified.

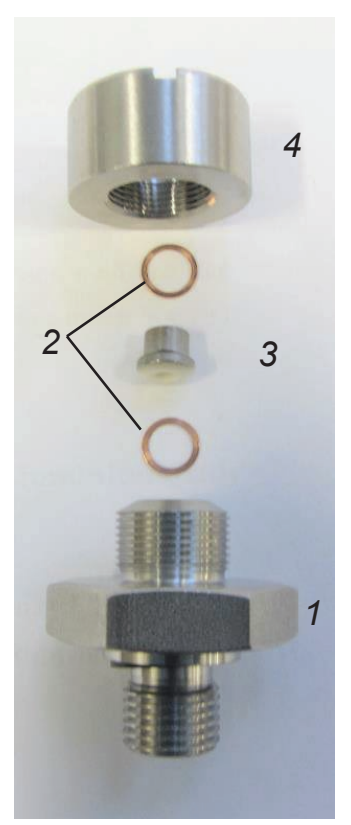

Fig. 7. Overview of the assembly, 1 threaded steel connector, 2 copper sealing rings, 3 ceramic measuring cell, 4 screw-on counterpart 


\section{Results}

The capacity of 100 bar was considered as the nominal pressure for both versions. With that pressure, both the alumina and zirconia ceramic cells have only approx. 0.25 per mille of strain. Due to the highly sensitive strain gauge film, we obtain already approx. 3 to $4 \mathrm{mV} / \mathrm{V}$ at that pressure. The hydraulic pressure was now increased continuously until the membranes were destroyed. Thus the burst pressure of the $\mathrm{ZrO}_{2}$ membrane was found to be approx. 900 bar, while $\mathrm{Al}_{2} \mathrm{O}_{3}$ broke already at approx. 220 bar. The maximum pressure was now set to 400 bar for zirconia and 160 bar for alumina in order to stay away from the limit of destruction. In Fig. 8 and 9 the bridge signals are shown as a function of the applied pressure for the zirconia and alumina version respectively. A sample of each version was measured three times with nearly identical results. The sensitivity was about $11 \mathrm{mV} / \mathrm{V}$ at 400 bar for the $\mathrm{ZrO}_{2}$ cell. For reference the functional layer was also deposited onto a glass substrate in the same sputtering process. The sensitivity on that glass reference provides the expected sensitivity of $16 \mathrm{mV} / \mathrm{V}$ at 1 per mille strain. Thus the sensitivity on the ceramic measurement cell is reduced by approximately $5 \mathrm{mV} / \mathrm{V}$. The reduction is probably due to the rougher surface of the ceramic and a difference of the sputtering geometry. An optimization would further increase the sensitivity on the ceramic surface.

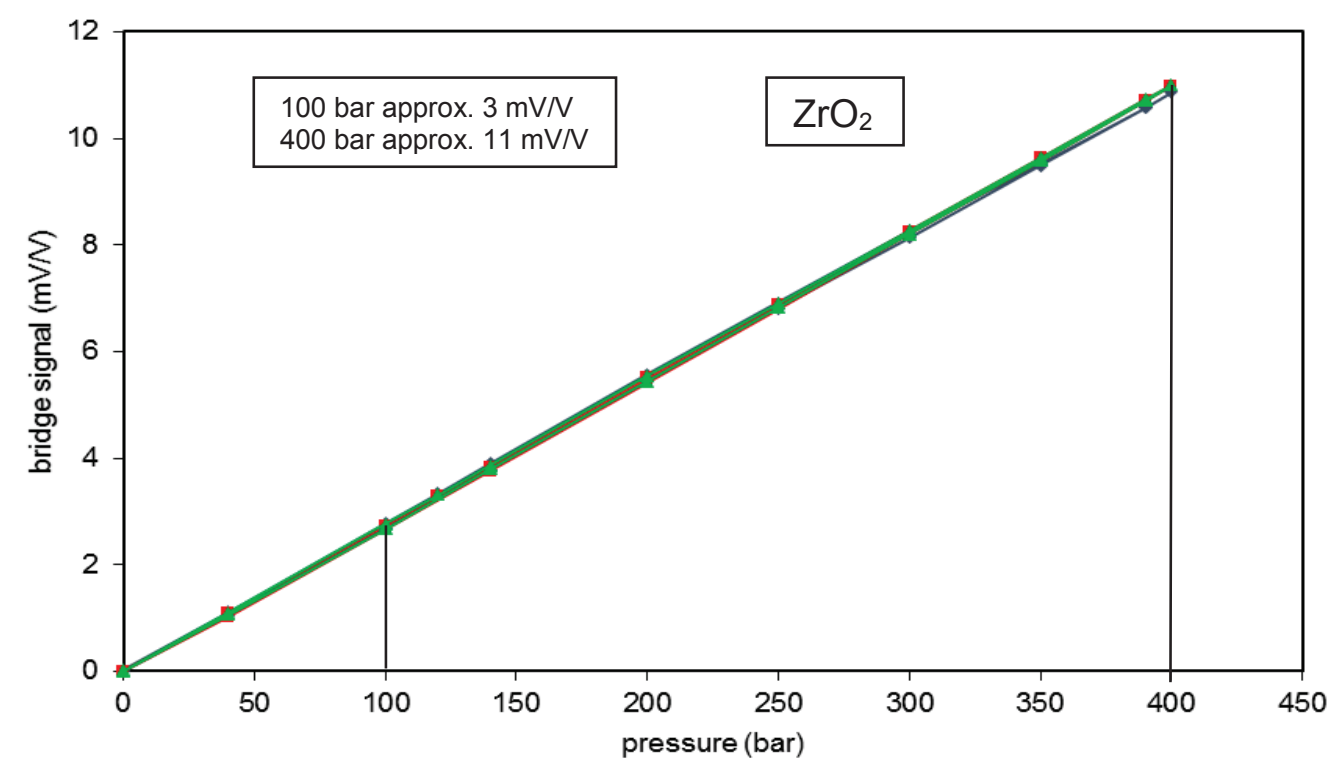

Fig. 8 Bridge signal of a $\mathrm{ZrO}_{2}$ ceramic sensor sample up to a pressure of 400 bar.

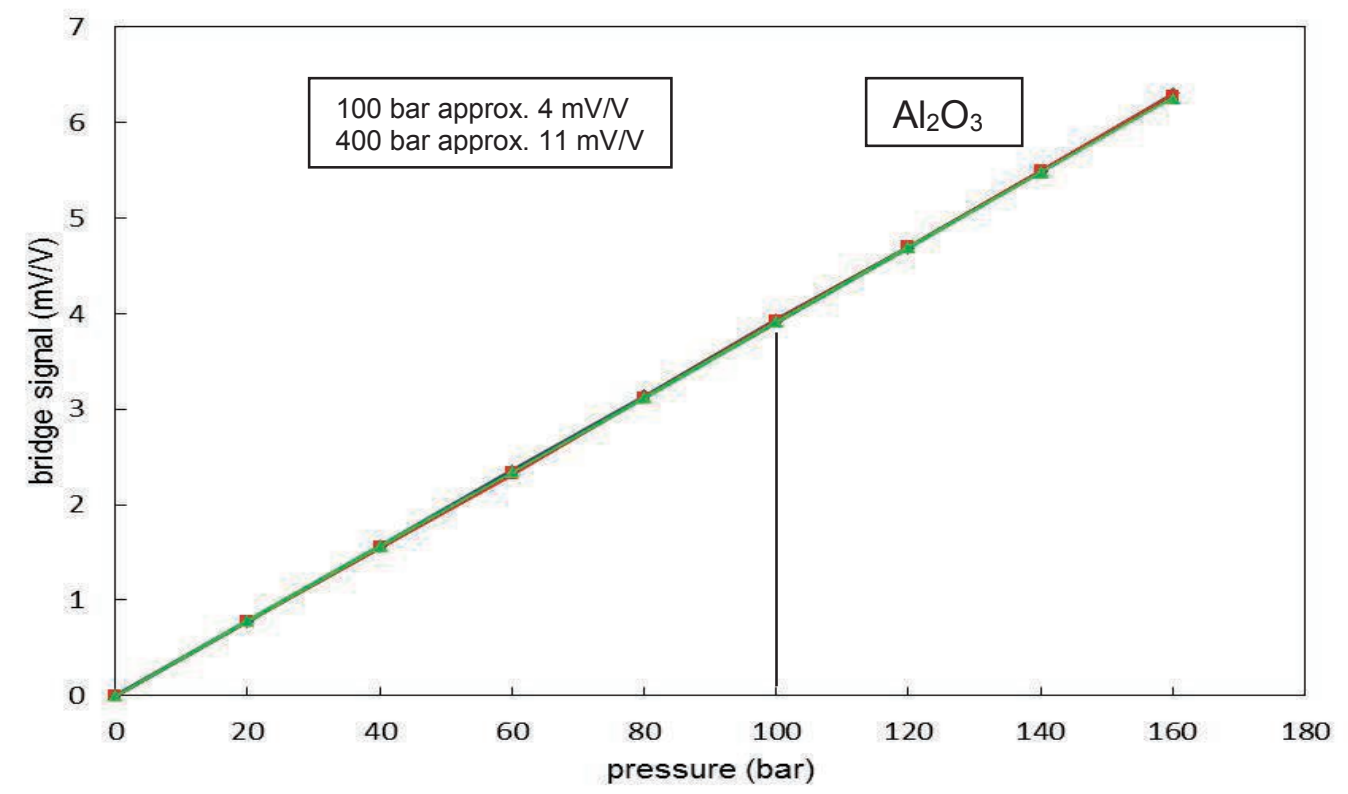

Fig. 9 Bridge signal of one $\mathrm{Al}_{2} \mathrm{O}_{3}$ ceramic sensor sample up to a pressure of 160 bar. 


\section{Discussion}

The laser-friendly design makes it possible to cut, in just a few seconds, a Wheatstone bridge into the functional layer. By using the laser as a structuring tool in combination with the patented layout as well as the direct bonding, the number of process steps for producing a pressure sensor is significantly reduced. Using $\mathrm{ZrO}_{2}$ or $\mathrm{Al}_{2} \mathrm{O}_{3}$ as a measuring cell avoids the complex PECVD process for insulating the steel membrane. Insulation faults due to pinholes and breakdown of the insulation layers cannot occur. The use of chemicals for lithographic processes is completely eliminated.

The two versions of alumina and zirconia were designed to develop the same value of strain, i.e. 1 per mille at a specified pressure. Due to different Young modulus, the alumina design has a $0.3 \mathrm{~mm}$ thick membrane, while $0.5 \mathrm{~mm}$ is necessary in the case of zirconia. It turns out, that the alumina version only withstands pressures of approx. 220 bar, while the zirconia holds up to 900 bar. Thus the alumina is much more prone to bending stress as zirconia. The measured ratio of burst pressures i.e. 900 bar to 220 bar is reflected by the values for the respective bending strengths given in table 1 . For zirconia to alumina we have $1200 \mathrm{MPa}$ to $350 \mathrm{MPa}$ which is very similar to the burst pressure ratio under the given uncertainties. This result shows that zirconia is superior to alumina in this application.

\section{Summary}

Our contribution reveals a new concept for pressure sensors with pressure ranges of some bar to approx. some thousand bar. The development of highly sensitive sensor layers is applied to employ ceramic materials for the sensor body. This in turn provides advantages in terms of applicability, manufacturing and performance.

Cutting the functional thin film on the ceramic $\mathrm{ZrO}_{2}$ cell by means of a uv-laser shows the feasibility of patterning without damaging the membrane of the ceramic cell. A patented laser friendly design to create a Wheatstone bridge provides a drastic simplification compared to common lithographic processes. In addition it is possible to place ultrasonic wedge bonds directly onto the functional films without the need for further contact layers.

Results are shown for cells of $\mathrm{ZrO}_{2}$ designed for a maximum strain of 0.25 per mille at a pressure of 100 bar. The output is $3 \mathrm{mV} / \mathrm{V}$ in this case ensuring a big and secure reserve to the measured burst pressure of 900 bar.
Further work is underway to improve the deposition and the assembling technology by means of resistance welding.

\section{References}

[1] MicroCeram, http://www.microceram.de, FO27_3_Gebrauchsanweisung und Sicherheitsinformationen Stand: 07/2014 Rev.5

[2] R. Koppert, S. Uhlig, H. Schmid-Engel, D. Göttel, A.-C. Probst, G. Schultes, U. Werner; Structural and physical properties of highly piezoresistive nickel containing hydrogenated carbon thin films; Diamond and Related Materials;vol. 25; pp. 5058, 2012

[3] Koppert R, Göttel D, Schultes G, Werner U. NanoNi@ C: Hochempfindliche Funktionsschicht für Druck-und Kraftsensoren. tm-Technisches Messen, 2010, 77(12), 631-637

[4] Patent: Sensorelement mit in vier Segmente unterteilter Sensorschicht und Verfahren zu dessen Herstellung, 2013, DE 102013011157.9

[5] D. Göttel, M. Cerino, G. Schultes, Highly sensitive pressure sensors with laser friendly Wheatstone bridge, Proceedings MikroSystemTechnik Kongress "Von Bauelementen zu Systemen": Aachen, Germany, 14.-16. October 2013, p. 757-760

\section{Acknowledgement}

This project has received a financial support from "Landesforschungsförderung des Saarlandes". The authors gratefully appreciate this assistance. 